\title{
What do aggregation results really reveal about group agency?
}

\author{
Brian Flanagan ${ }^{1}$
}

Published online: 13 January 2017

(C) Springer Science+Business Media Dordrecht 2017

\begin{abstract}
Discoveries about attitude aggregation have prompted the re-emergence of non-reductionism, the theory that group agency is irreducible to individual agency. This paper rejects the revival of non-reductionism and, in so doing, challenges the preference for a unified account, according to which, agency, in all its manifestations, is rational. First, I offer a clarifying reconstruction of the new argument against reductionism (due to Christian List and Philip Pettit). Second, I show that a hitherto silent premise, namely, that an identified group intention need not be determined by member attitudes according to a rule, e.g., majority, is false. Third, I show that, on rejecting this premise, the aggregation results lead instead to the conclusion that, in contrast to individual agency, group agency is non-rational.
\end{abstract}

Keywords Group agency · Collective intentionality · Judgement aggregation · Social ontology $\cdot$ Reductionism · Discursive dilemma

There are many scenarios in which a set of individual acts appears to constitute a group act rather than merely a sum of individual acts. Accounting for this appearance, theorists posit that a group itself may act. Some scenarios feature member-wide consensus on the act's performance, e.g., a sports team executing a pass play (Searle 1990), a team of volunteers painting a house (Bratman 1992), a couple walking on a beach (Gilbert 1990). Accordingly, theorists agree that a group may act if, '[e]ach participant... wills [the shared activity]' (Roth 2010). But whilst sufficient for group action, member unanimity is not necessary. Scenarios that

Brian Flanagan

brian.flanagan@nuim.ie;

https://www.maynoothuniversity.ie/law/our-people/brian-flanagan

1 Department of Law, Maynooth University, Maynooth, Co Kildare, Ireland 
feature member disagreement may similarly prompt ascription of a group act, e.g., scenarios featuring votes by the members of corporate boards, legislative chambers and collegiate courts. Thus, it is said that, equally, a group may act if the group itself, that is, the board, the senate, or the court, forms an appropriate intention (e.g., Copp 1995; Pettit 2001; Kornhauser and Sager 2004). It follows that group agency is instantiated by both unanimous and non-unanimous acts. The ontological issues concern, on the one hand, the relation between a group member's intention that a particular act be collectively performed and the ordinary intentions involved in her individual agency, and, on the other, the relation between a group's attitudes and those of its members.

Non-reductionism about unanimous group agency is the view that a group member's intention that a particular act be collectively performed is a primitive attitude (e.g., Searle 1990). Reductionism about unanimous agency holds, to the contrary, that such intentions are determined by one's ordinary individual intentions (e.g., Bratman 1992). Conversely, non-reductionism about non-unanimous agency denies that a group's intention is determined by its members' attitudes according to a rule, such as by majority (e.g., List and Pettit 2006; Schweikard 2008). The reductionist about non-unanimous agency holds, in contrast, that a group's intention is rule-determined (e.g., Copp 1995; Kornhauser and Sager 2004). At issue in each debate is whether reductionism succeeds in avoiding, 'an additional premium for explaining the same phenomena' (Tenenbaum 2015, 3379), namely, the group acts ascribed in practical discourse. Lately, non-reductionism about non-unanimous group agency has become newly influential (Schweikard and Schmid 2013). This paper revisits the argument prompting its revival. The argument in question does indeed reveal something about the nature of group agency, but it is not what nonreductionists think. ${ }^{1}$

Contemporary non-reductionism is the product of technical inquiry into the aggregation of attitudes. The results of this inquiry have led to the positing of what we shall call the, 'rationality-reducibility dilemma': that not all group intentions identified in discourse are both rational and rule-determined. Following Christian List and Philip Pettit, many take this dilemma to support the conclusion that not all identified group intentions are rule-determined. Such reasoning relies on a silent assumption, namely, that an identified group intention need not be rule-determined. This assumption proves to be problematic.

Next to the analogy between the rationality of individual and group agency is an analogy between the determination by physical processes of individual attitudes and the determination by member attitudes of group attitudes. The latter analogy, while venerable, obscures a critical disparity in the means by which individual and group attitudes may be identified. We come to know an individual's attitude without reference to its determinants. Through an individual's first-person testimony, we rely instead on an individual's special access to her own attitudes. Due to the

\footnotetext{
${ }^{1}$ Henceforth, 'non-reductionism', will refer solely to non-reductionism about non-unanimous group agency.
} 
inability of groups to give first-person testimony, a comparable means of identifying a group's attitude is unavailable. Consequently, it seems that, unlike individual intention, group intention may only be identified by reference to its determinants. The significance of the rationality-reducibility dilemma must therefore be revisited. It turns out that, rather than showing that not all group intentions are ruledetermined, it shows, instead, that not all group intentions are rational.

Recent technical results do advance the debate on the nature of group agency, and, hence, rightly guide both positive political theory (e.g., Vermeule 2011), and normative inquiries into matters of institutional design (e.g., Chilton and Tingley 2012) and corporate responsibility (e.g., Hess 2014). But they do so in an unexpected way. Rather than revealing that non-reductionism alone can explain the pertinent phenomena, what they really reveal is that it is, after all, 'wrong to attempt to establish a parallel... in which the collectivity is... governed by the same principle of rationality as the individual' (Coleman 1972, 212). The analogy between the rationality of individual and group agency comes naturally; in consequence, it has escaped deserved scrutiny. We find that, properly construed, the aggregation results suggest that, to preserve a useful notion of group agency, some features of the model of rational individual agency must be jettisoned. Paradigmatic group intentions are not all wholly rational.

\section{Rejecting reductionism}

This first section presents a clarifying reconstruction of List and Pettit's argument for non-reductionism. Clarity is advanced in three respects, each pertaining to List and Pettit's defence of the argument's first primary premise, that, if all identified group intentions are rational, then not all identified group intentions are ruledetermined. First, the reconstruction makes explicit the sub-argument that supports this premise comprising List and Pettit's claims about attitude aggregation and discourse about groups. Second, the resultant clarity on the structure of this subargument reveals that it incorporates a silent assumption, to wit, that an identified group intention need not be rule-determined. Having acknowledged this assumption, we are better placed to assess the plausibility of List and Pettit's overall argument for non-reductionism. Third, the reconstruction distinguishes one way in which List and Pettit interpret their own notion of a, 'straw vote procedure', namely, as just another sort of rule. Distinguishing group intentions determined by a, 'straw vote procedure', as thus interpreted from group intentions that are not ruledetermined facilitates assessment of the (hitherto silent) assumption that an identified group intention need not be rule-determined. The second section presents an assessment of this assumption.

Statements 1-3 (S1-3) comprise List and Pettit's primary argument:

1. If all identified group intentions are rational, then not all identified group intentions are rule-determined

2. All identified group intentions are rational 
Hence,

3. Not all identified group intentions are rule-determined

Consider S1 and S2 in turn.

\section{S1}

In defence of the premise that, if all identified group intentions are rational, then not all identified group intentions are rule-determined, List and Pettit offer the subsidiary argument SI-1:

I. If discourse successfully identifies group intentions, then not all identified group intentions are both rational and rule-determined

II. Discourse successfully identifies group intentions

Hence,

III. Not all identified group intentions are both rational and rule-determined Hence, S1:

1. If all identified group intentions are rational, then not all identified group intentions are rule-determined

SI

The premise that, if discourse successfully identifies group intentions, then not all identified group intentions are both rational and rule-determined (SI), presupposes that a rational group intention is one which is rationally related to the agent's beliefs about the justifications for performing the act in question: a [rational] collective... act[s] in pursuit of a single set of desires, in accordance with a single set of beliefs [List and Pettit 2011, vii (henceforth 'LP')]. This reflects our understanding of a rational individual intention as one determined, 'on the basis of an overall practical assessment of [one's] options and opportunities' (Shpall and Wilson 2012). (We shall later discover that we have reason to adopt an alternative model of group rationality.) SI derives its key support from a mathematical insight into the aggregation of attitudes.

Inquiry into attitude aggregation has yielded a series of impossibility results. These reveal that, even where individual member attitudes are themselves mutually consistent, there is no rule, bar dictatorship, by which member intentions and beliefs always determine mutually consistent group intentions and beliefs (summarized in LP 66-67). This finding is known as the, 'discursive dilemma' (LP 46). Some rules will resolve the initially inconsistent group attitudes which they generate. But, crucially, any resolution of a set of inconsistent attitudes into a set of rational 
attitudes involves reflection on the part of the agent, i.e., 'to and fro adjustment... going back and forth between different mutually inconsistent judgments... to decide where to adjust' [LP 61 (citing Rawls 1971)].

Certain rules resolve the initial inconsistencies to which they give rise in ex ante fashion. For instance, a rule might specify that, in case of inconsistency, the group's intention is the intention that is implied by the group's beliefs about the applicable justifications: tak[e] certain propositions as... potential premises... and let[] the... majority-determined views on those premises dictate the collective view to be taken on the conclusion (List and Pettit 2002, 105). Alternatively, a rule might specify that, in case of inconsistency, the group's intention is determined by its chairman alone: the plenipotentiary might have the... power of deciding how the group should go in the event of a paradox arising (List and Pettit 2002, 103). Neither such resolution of attitudinal inconsistency involves reflection on the part of the agent, however. Accordingly, such rules are not guaranteed to determine attitudes that are rational, as opposed to merely consistent. Still, not all rules resolve inconsistency in a way that excludes reflection. List and Pettit describe an alternative, the, 'strawvote procedure' (SVP):

[C]onsider all the different possible ways in which previously formed attitudes or the new attitude could be revised so as to restore consistency. Take a vote under a suitable procedure... on which of the possible revisions to make (LP $62)$.

Rather than excluding reflection on the part of the agent, SVPs would resolve attitudinal inconsistencies by determining a further, bespoke, which-attitude-torevise group attitude. For instance, an SVP might specify that, in case of inconsistency, the group intention is determined by the majority belief on which group attitude to revise. ${ }^{2}$ Though itself rule-determined, the group's which-attitudeto-revise attitude would be the product of the group's reflection on the particular inconsistency at issue. Presumably, an SVP-resolved group intention would therefore qualify as rational. But the possibility of rules that resolve inconsistency in a reflective fashion is one thing; whether, in ascribing group intention, we actually refer to such rules, is another. ${ }^{3}$

In general, we do not ascribe group attitudes by reference to an SVP (LP 64). When, for instance, inconsistent majority attitudes emerge on a collegiate court of law, no further vote is taken on which majority attitude to revise (Kornhauser and Sager 1986, 115). Nonetheless, the inability of alternative rules to guarantee

\footnotetext{
2 Such a procedure resembles that described in Pettit 2003 (161), which draws, in turn, on the suggestion in Kornhauser and Sager 1993 (33-36).

3 Moreover, a limitation to the SVP just described is that, over three or more alternatives, the majority attitudinal relation may be intransitive (alternative $x$ is preferred to $y, y$ is preferred to $z$, and $z$ to $x$ ) (Condorcet 1785). Hence, the rule might fail to resolve a set of initially inconsistent attitudes into a set of rational attitudes because it yields an intransitive further attitude over the revisional alternatives: intention $>$ belief about justification ${ }_{1}$; belief about justification $>_{1}$ belief about justification $_{2}$; belief about justification $2>$ intention.
} 
rationality fails to check the invocation of group intention, 'in common and in scientific discourse' (LP 4). It follows that the group intentions actually invoked in discourse could not all qualify as being both rational and rule-determined. It follows, in turn, that, if discourse successfully identifies group intentions, then not all identified group intentions are both rational and rule-determined (SI).

\section{SII}

Ideally, the theory of group agency would redeem rather than repudiate our, 'talk of group agents' (LP 5). We assume, therefore, that discourse does successfully identify group intentions (SII): the ascription of agency to groups expresses a correct and important observation (LP 4).

\section{SIII}

Assuming, first, that if discourse successfully identifies group intentions, then not all identified group intentions are both rational and rule-determined (SI); and, second, that discourse successfully identifies group intentions (SII), it follows that not all identified group intentions are both rational and rule-determined (SIII):

[T] he attitudes... we need to ascribe to any group that meets the conditions of [rational] agency are not readily reducible to the attitudes of individuals (LP 5).

The proposition that not all identified group intentions are both rational and ruledetermined (SIII) may be described as the rationality-reducibility dilemma. The dilemma's importance lies in its support for the first premise of List and Pettit's primary argument for non-reductionism (S1): if all identified group intentions are rational, then not all identified group intentions are rule-determined. List and Pettit appear to seek to deduce S1, '[I]f a group agent is to display... rationality... [then] its attitudes cannot be a majoritarian or other equally simple function of the attitudes of its members (LP 8)', from the rationality-reducibility dilemma alone:

III. Not all identified group intentions are both rational and rule-determined

Hence, S1:

1. If all identified group intentions are rational, then not all identified group intentions are rule-determined

The inference from SIII to S1 is problematic. It might be the case that, to be identified, a group intention must be rule-determined. If so, then, contrary to the premise that, if all identified group intentions are rational, then not all identified group intentions are rule-determined (S1), but consistently with the conclusion that not all identified group intentions are both rational and rule-determined (SIII), there is no scenario in which an identified group intention could fail to be ruledetermined. Therefore, the argument SIII-1 must introduce the further premise that an identified group intention need not be rule-determined (SIV). 
SIV

The rationality-reducibility dilemma implies that, if all identified group intentions are rational, then not all identified group intentions are rule-determined (S1), just in case an identified group intention need not be rule-determined (SIV). Whilst they fail to introduce SIV as a step in their argument, List and Pettit do remark that: [W]e will be unable to recognize the kind of group agent we have in mind as an agent... if we keep our gaze fixed at the level of individuals (LP 76). The implicature is that we are able, in principle, to recognize group intentions that are not rule-determined, and, hence, that an identified group intention need not be ruledetermined (SIV). Accordingly, we integrate SIV into SIII-1:

III. Not all identified group intentions are both rational and rule-determined

IV. An identified group intention need not be rule-determined

Hence, S1:

1. If all identified group intentions are rational, then not all identified group intentions are rule-determined

\section{S2}

S2 states the common assumption that all identified group intentions are rational: [W] can deal with a group agent as if it were an individual person' (LP 13). S2 is justified on the basis that discourse recognizes rational group agency only: [W]e regard a group as an agent just when we think something is amiss if [its] attitudes are inconsistent, or otherwise irrational (LP 39).

\section{S3}

Taken together, the respective premises that, if all identified group intentions are rational, then not all identified group intentions are rule-determined (S1), and that all identified group intentions are rational (S2), imply that not all identified group intentions are rule-determined (S3): [O]n some matters the attitudes embraced by a group agent are not a systematic function of the attitudes of members (LP 10). Accordingly, the initial technical insight that rules may determine inconsistent group attitudes (the discursive dilemma) leads ultimately to the ontological conclusion that group attitudes, 'are not... reducible', to individual attitudes (LP 76-77). S1-3 vindicates the view that the determination of a group's intention may merely, 'turn out to mimic some [rule]... implementation [of which] is a consequence of the functionally inexplicit organizational structure' (LP 61-62).

The foregoing reconstruction of List and Pettit's argument for non-reductionism achieves three points of clarification, each pertaining to the defence of the argument's first primary premise, that, if all identified group intentions are rational, then not all identified group intentions are rule-determined (S1). ${ }^{4}$ The first point of

\footnotetext{
${ }^{4}$ There is a forerunner to List and Pettit's mature argument which fails to deliver a repudiation of reductionism:
} 
clarification consists in the explicit specification of the logical function of List and Pettit's claims about attitude aggregation and group agency talk. Thus, SI-1 renders transparent the reasoning leading from the discursive dilemma (SI) to the rationality-reducibility dilemma (SIII), and, finally, to the premise that, if all identified group intentions are rational, then not all identified group intentions are rule-determined (S1). The second point of clarification consists in the acknowledgement of a premise on which the defence of S1 silently relies, namely, that an identified group intention need not be rule-determined (SIV). Without SIV, S1 cannot be derived from the intermediate conclusion that not all identified group intentions are both rational and rule-determined (SIII).

The third point of clarification is interpretive. Our discussion of the claim that, if discourse successfully identifies group intentions, then not all identified group intentions are both rational and rule-determined (SI) involves a regimentation of List and Pettit's notion of the straw vote procedure. Officially, List and Pettit characterize SVPs as non-rule functions (LP 62). However, in their stated example of an SVP, quoted above, what they in fact describe is the determination of group attitudes according to a particular type of rule. Naturally, we are free to interpret the notion of the SVP as we please. But any assessment of the claim that an identified group intention need not be rule-determined (SIV) that mistook our identification of SVP-example determined group intentions for the identification of group intentions that are not rule-determined would be unreliable. By distinguishing SVP-example type rules from non-rule functions, we avoid such potential confusion.

In the second section, we duly assess the claim that an identified group intention need not be rule-determined (SIV) and find it to be false. The consequence is not just that List and Pettit's argument fails to prove non-reductionism but also that their claims about attitude aggregation and practical discourse imply that group agency is not wholly rational.

Footnote 4 continued

First premise: there is no intention without a minimum of rationality on the part of the relevant agent. Second premise: collectives can display that minimum of rationality only insofar as they collectivise reason, as I shall put it. Conclusion: only groups that collectivise reason can properly have intentions (Pettit 2001, 241).

Pettit's second premise (2001) corresponds to S1. But it is different in two respects. It is stronger in that it asserts that rational group intentions could not be rule-determined. (It is unclear how this assertion may be derived from the discursive dilemma, i.e., from the insight that rules are liable to determine inconsistencies.) Crucially, it is also weaker than S1: it does not refer to actual group intentions. Pettit's conclusion (2001) is accordingly weaker than List and Pettit's (2011) conclusion that not all identified group intentions are rule-determined (S3). Unlike S3, it does not state that groups do have intentions that are not rule-determined. Instead, it leaves open the possibility that we ought to consider groups to lack intentions whenever the alternative is to posit intentions that are not rule-determined. Pettit's original syllogism thus fails to establish that group attitudes, 'are not a systematic function of the attitudes of members' (LP 10). Pettit 2001 notably proceeds, nevertheless, to endorse S3: [M]any collectivities will [collectivize reason] [250 (emphasis added)]. 


\section{Rejecting rationality}

Though its discovery was spurred by interest in the nature of group agency, the discursive dilemma does not in itself shed light on the subject. It does so only granted the claims about the content and the philosophical status respectively of discourse about group agency reflected in SI and SII. Even then, the resultant insight takes the form of a further dilemma, that not all identified group intentions are both rational and rule determined (SIII). Any consequent insight to which the rationalityreducibility dilemma might itself give rise depends on the assumption that an identified group intention need not be rule-determined (SIV). If so, then the dilemma ultimately establishes, as anticipated, the irreducibility of group agency. If, conversely, an identified group intention must be rule-determined, then the dilemma establishes, instead, that group agency is not wholly rational. Recall List and Pettit's implicit endorsement of the assumption that an identified group intention need not be rule-determined:

[W]e will be unable to recognize the kind of group agent we have in mind as an agent... if we keep our gaze fixed at the level of individuals. We will fail to see the wood for the trees. (LP 76)

It turns out that the kind of group agent that is revealed at the level of individuals is the only kind of group agent that we are able to recognize. This limitation is obscured by an enduringly attractive analogy between the determination of individual and group attitudes respectively:

The conception of the relationship which unites the social substratum and the social life is at every point analogous to that which undeniably exists between the physiological substratum and the psychic life of individuals (Durkheim 1953, 25).

The analogy appears in a current register in the suggestion that patterns in the behaviour of groups are, 'as elusive at the individual level as the patterns in the behavior of individuals are elusive at the neuronal' (Pettit 2014, 1655; similarly, LP 78). ${ }^{5}$ In contrast to individuals' attitudes, however, if groups' attitudes are elusive at the determinant level, they are irredeemably so. In the case of groups, if not individuals, it seems that we cannot see the wood but for seeing the trees.

We come to know an individual's attitudes through her behaviour, including, notably, her testimony. We do so without reference to the internal physical processes that actually determine her attitudes. We simply trust what she says about them on the assumption that, 'of [her] own thoughts [she] cannot but be aware'

\footnotetext{
5 Deborah Tollefsen extends Durkheim's analogy explicitly by employing Daniel Dennett's notion of descriptive 'efficiency':
}

[T]here is an [intentional] description of human behaviour that is more efficient than a description that cites microphysical properties... [Equally] there are patterns that are missed if one attempts to explain the social world by appealing only to individual intentional states [Tollefsen 2002, 43 (citing Dennett 1991)]. 
(Wright 2012, 402). Accordingly, individual attitude is identifiable irrespective of how it is determined. Obviously, groups, unlike individuals, cannot speak (or otherwise behave) for their own part. It is suggested that we gain access to a group's attitudes through third-person testimony, that is, through what is said on a group's behalf by individuals: Just as I may say of myself... so the spokespersons for a group agent may say of it... (LP 182). The question is whether testimony also allows us to learn a group's attitude without reference to its determinants. If so, then, similarly, group attitude is identifiable irrespective of how it is determined, and, hence, an identified group intention need not be rule-determined (SIV).

It is true that, all things being equal, one is worse off relying on the spokesperson's testimony than on that of the principal. The inferiority of thirdperson testimony has been said to leave groups at a disadvantage in respect of the performance of speech acts:

[The] spokesperson may make mistakes in their interpretation of the corporation's attitudes in a way that has no equivalent to the singular case... [she may] misread the instruction given to her by the CEO, or some such... Thus... [her role] is far from being on a par with... first person authority... (Schmid 2014, 1696-97)

Still, in principle at least, reliance on third-person testimony does not require knowledge of how attitudes are actually determined. Take the case of the individual principal, e.g., a prime minister. While we are unable to say of the spokesman that he, 'cannot but be aware', of the prime minister's attitudes, we can say so of the prime minister herself. We may expect the spokesman, and, therefore, the public, to discover the prime minister's attitude through the prime minister's private utterances without reference to its neuronal determinants. It is believed that thirdperson testimony allows us to learn a group's attitude on a comparable basis:

[W]hen we explain your attitudes by the evidence to hand... we register information that would not have been readily available... at the neuronal level... This... argues equally... for regarding group[s]... as agents in their own right (Pettit 2014, 1654).

Third-person testimony in fact fails to provide equivalent access to the attitudes of individuals and groups. This is because a subject's self-knowledge, on which all testimonial identification of individual attitudes ultimately depends, may be the subject of first-person testimony only.

Self-knowledge refers to knowledge of one's own mental states, including one's attitudes. It contrasts with knowledge of the external world, including, notably, the attitudes of others. Following our folk concept, most philosophers accept that one may arrive at self-knowledge by accessing one's mental states in a way that is exclusively available to oneself (Gertler 2015). The existence of an exclusive means of self-knowledge divides knowledge of others' attitudes into the parasitical and non-parasitical. Parasitical knowledge relies on the subject's exclusive means of access. Non-parasitical knowledge, in contrast, relies on non-exclusive access, such as on the subject's (non-testimonial) behaviour, on social scientific generalization, or on the statuses of its attitudes' determinants, e.g., the neuronal activities of a 
subject's brain. ${ }^{6}$ Parasitical knowledge of a subject's attitude is enabled by testimony: [A]vowals are thought to capture a special form of self-knowledge that has private origins (Bar-On and Long 2003, 179). It is by enabling parasitical knowledge that testimony allows us to learn a subject's attitude without reference to its determinants. Crucially, testimony can only enable knowledge, parasitical or otherwise, if the entity in sole possession can speak its own mind.

To attain through testimony any knowledge of which some entity is in sole possession, the entity in question must be able, on its own behalf, to testify as to what it knows. A chain of testimony ending in a third party's opinion is insufficient. Thus, we are only able to explain our identification of individuals' attitudes as parasitical knowledge because individuals may speak for themselves. Conversely, we are unable to similarly explain our identification of group attitudes because groups, in contrast, cannot speak for themselves. Even if a group, like an individual, possessed exclusive access to its attitudes, being unable to convey anything for itself, it could not share what it had learned. Any analogy between the determination of individual and group attitudes is liable to obscure this disparity. It is an individual's ability to give first-person testimony which allows us to identify her attitude without reference to its determinants; groups are not similarly endowed.

Parasitical knowledge of a group's attitude is unavailable. In its absence, identifying a group's attitude means referring to its determinants. Thus, a group's attitude is identifiable only if it is a function of something more basic, namely, member attitudes. This implication undermines the theory that a group's intention is an emergent, 'living force' (Figgis 1913, 40; similarly, Rovane 2014). The achievement of ontological parsimony has already persuaded most contemporary theorists (e.g., Searle 1990) to reject such theories, including, notably, List and Pettit: the agency of group agents depends wholly on the organization and behavior of individual members (LP 4). ${ }^{7}$ But emergentism is not the only variety of nonreductionism that is undermined by the fact that identifying a group's attitude means referring to its determinants. Non-reductionist theories that acknowledge that a group's intention does indeed depend on its members' attitudes are equally vulnerable.

Crucially, to identify an entity's attitude by reference to its determinants, the entity's attitudes must be determined according to a rule. Members' (first-person) testimony, i.e., their votes, allows us parasitical knowledge of the respective statuses of the individual member attitudes on which the group's attitude depends. But the profile of members' attitudes on a particular question can indicate a group attitude only if we know which profiles suffice for a given group attitude to obtain. Such knowledge, in turn, requires knowledge of the rule with which the determination of

\footnotetext{
${ }^{6}$ As a practical matter, of course, parasitical knowledge is indispensable. Non-testimonial behaviour may provide a basis for ascribing attitudes such as anger or arousal, but not a decision to prohibit the sale of a drug or to offer a particular contract. Neuroscience is equally unable to discern such attitudes. Social scientific generalization, in turn, relies on parasitical knowledge of the attitudes of the sample population.

${ }^{7}$ Emergentism fails to, 'keep[] down the number of fundamentally different kinds of entity' (Lewis 1973, 87).
} 
the group's attitudes by members' attitudes accords. ${ }^{8}$ For instance, to know that the existence of a majority member attitude on a particular question suffices for a corresponding group attitude to obtain, we must know that the group's attitudes are determined by the majority member attitude. Thus, to proceed to identify a group's attitude from members' attitudes, members' attitudes must determine the group's attitudes according to a rule. It follows that, in the absence of any alternative to identifying a group's attitude by reference to its determinants, an identified group attitude, notably, an identified group intention, must be rule-determined, that is, derivable from an explicit, 'organizational structure'.

Strictly, a theory of group agency need not aspire to explain practical discourse about group acts. It is for that reason that non-reductionism is merely undermined, rather than flatly refuted, by the fact that an identified group intention must be ruledetermined. Nevertheless, the described aspiration seems crucial to such a theory's plausibility (Copp 1980, 581). In its absence, it would be unclear what purpose the addition of the pertinent subcategory of agency would serve. Conversely, the reducibility of identified group intentions has immediate relevance for the interpretation of the rationality-reducibility dilemma: Not all identified group intentions are both rational and rule-determined (SIII). Any insight that the dilemma yields depends on what we otherwise know to be true of such intentions. The fact that they must be rule-determined entails that the dilemma fails to support the first primary premise of List and Pettit's argument for non-reductionism, namely, that, if all identified group intentions are rational, then not all identified group intentions are rule-determined ( $\mathrm{S} 1)$. On the contrary, it follows, instead, that the dilemma implies that not all such intentions are rational $(\neg \mathrm{S} 2)$ :

A. Not all identified group intentions are both rational and rule-determined (SIII)

B. An identified group intention must be rule-determined ( $\neg$ SIV)

Hence,

C. Not all identified group intentions are rational $(\neg \mathrm{S} 2)$

Given the rationality-reducibility dilemma, rejection of the assumption that an identified group intention need not be rule determined leads to the conclusion that not all identified group intentions are rational (C). This conclusion is striking for contradicting $\mathrm{S} 2$, the common theoretical assumption that group agency, like individual agency, is rational. In principle, it might be thought that this result is paradoxical.

Notice that the conclusion that not all identified group intentions are rational refers solely to the full-dress kind of rationality associated with individual intentions. The rationality-reducibility dilemma, on which that conclusion depends, itself derives from SI, the premise that, if discourse successfully identifies group intentions, then not all identified group intentions are both rational and rule-

\footnotetext{
${ }^{8}$ If the rule is subject to a defeating condition, e.g., that, if rule-specified attitudes are irrational, then no attitude is properly determined, then knowledge of this condition is evidently also necessary.
} 
determined. SI, recall, presupposes that a rational group intention is rationally related to the agent's beliefs about the justifications for performing the act in question. Accordingly, the conclusion that not all identified group intentions are rational (C) states only that not all identified group intentions are rationally related to the agent's beliefs. Thus, if we assume that, unlike an individual intention, a group intention need not be rationally related to beliefs but need only satisfy more minimal rationality conditions, then $\mathrm{C}$ is consigned to triviality. The question prompted by $\mathrm{A}-\mathrm{C}$, therefore, is not whether it is paradoxical that there are group intentions that are altogether irrational but merely whether it is paradoxical that there are group intentions that are not rationally related to beliefs. There seems little reason to think that it is.

The premise that, if discourse successfully identifies group intentions, then not all identified group intentions are both rational and rule-determined (SI) is based in part on an observation about the content of discourse, namely, that the inability of rules to guarantee rationally related group attitudes fails to check ascription of group intention. Equally, it is possible to test whether our reluctance to ascribe nonrational individual intentions does actually extend to group intentions (LP 40). A group's intention is commonly ascribed on the basis of the same voting procedure in every case. Thus, group intention is not only ascribed notwithstanding any inconsistency to which the pertinent rule gives rise but is ascribed in perceived reliance on that rule. ${ }^{9}$ In principle, this practice might be the result of a mistaken assumption that the rule has not, in fact, given rise to inconsistency. But this explanation overlooks cases featuring explicit intention-belief inconsistency. A prominent example is the ascription of collegiate court decisions on the basis of a majority of members' decision votes even as members' published reasons indicate inconsistent majority beliefs (Kornhauser and Sager 1993, 21). ${ }^{10}$ Thus, whereas our observed willingness to ascribe group intentions supports SI, it suggests, equally, that group intention, unlike individual intention, need not be rationally related to the agent's beliefs. It seems, therefore, that an approach that distinguishes the minimalist rationality of group intention from the full-dress rationality of its individual counterpart is not paradoxical. Such an approach would render the disjunction between rule-determinacy and full-dress rationality (A-C) unproblematic. Moreover, we find no equivalent disjunction between rule-determinacy and minimalist rationality.

Our willingness to ascribe group intentions does not extend to those that are completely irrational. Thus, it is difficult to conceive of an intransitive intention, individual or group, over multiple alternatives. We know from Condorcet's scenario, in which majorities prefer alternative $x$ to $y$, alternative $y$ to $z$ and $z$ to $x$,

\footnotetext{
9 This is consistent with List and Pettit's primary premise that, if all identified group intentions are rational, then not all identified group intentions are rule-determined (S1). Grant that an identified group intention need not be rule-determined (SIV). If so, one might, in principle, identify a rational group intention that is not rule-determined even while mistakenly thinking that one had relied on a rule.

${ }^{10}$ Exemplified in the US Supreme Court case of National Mutual Insurance Co. v. Tidewater Transfer Co. (1949) 337 United States Reports 582, of which, dissenting Justice Felix Frankfurter observed, 'conflicting minorities in combination bring to pass a result' (665).
} 
that rules by which member attitudes determine group intentions need not guarantee a transitive intention. In contrast to cases featuring explicit intention-belief inconsistency, the ascription of a group intention in Condorcet's scenario is standardly considered problematic. Crucially, however, while tallying decision votes alone will not reveal a rule's derivation of inconsistent group beliefs, it will reveal a rule's derivation of an intransitive intention. Consequently, a rule's inability to guarantee transitivity should check ascriptions of group intention. It follows that the discovery of the impossibility of any rule that satisfies a set of conditions that includes such a guarantee (Arrow 1950) does not support a claim that, if discourse successfully identifies group intentions, then not all identified group intentions are both transitive and rule-determined. Hence, Arrow's result fails to provide a foundation for an A-C-equivalent argument for the (genuinely paradoxical) conclusion that not all identified group intentions are transitive. The disjunction between rule-determinacy and full-dress rationality is not accompanied by a further disjunction between rule-determinacy and minimalist rationality. Accordingly, an alternative minimalist model of group rationality is available which is neither paradoxical nor is, itself, the subject of a paradox.

The described disjunction between rule-determinacy and full-dress rationality threatens the ostensibly reasonable pursuit of a fully unified theory of agency: an account of collective action should be based upon the most successful accounts of individual action (Chant 2007, 245). In principle, we might eliminate this threat by rejecting one of the disjunction's constituent assumptions. In light of the argument outlined above, we shall take it that questioning the premise that an identified group intention must be rule-determined (B) is off-limits. That leaves the rationalityreducibility dilemma, that not all identified group intentions are both rational and rule-determined (variously denoted as A and SIII). The dilemma is jointly implied by the premises SI, that, if discourse successfully identifies group intentions, then not all identified group intentions are both rational and rule-determined, and SII, that discourse successfully identifies group intentions. Abandoning SI means rejecting the theoretical consideration from which it derives, to wit, that rules are unable to always determine group intentions that are rationally related to group beliefs. The aggregation results render rejection of this consideration equally offlimits. Abandoning SII might not, in contrast, be off-limits but it would leave unclear what purpose the addition of a subcategory of non-unanimous group agency might serve. Moreover, abandoning SII would, in turn, make it arbitrary to favour a theory of individual agency that is vindicated by discourse about individual acts, i.e., one that states that individual intentions must exhibit full-dress rationality.

Preserving a fully unified account of individual and group action by seeking to dissolve the disjunction between rule-determinacy and full-dress rationality is unavoidably costly. Accordingly, it may be preferable to abandon such an account in favour of one that incorporates a minimalist model of group rationality that consists merely in conditions such as transitivity. On this approach, the disjunction reveals that, in fact, the most successful accounts of individual and group action diverge. 


\section{Conclusion}

Recent discoveries about attitude aggregation have attracted deserved attention for revealing a dilemma in the theory of group agency: group agency cannot be both wholly rational and reducible to individual attitudes. Thus far, the dilemma has prompted a rejection of reductionism. We saw that this response, due to Christian List and Philip Pettit, rests on a silent assumption about the means available to identify a group's intention. This assumption turns out to be false. The dilemma's failure to refute reductionism has significance beyond the immediate ontological question. It removes a perceived motivation both for an alternative positive political theory and for the extension to groups of moral responsibility. Moreover, we are left with a choice between dissolving the dilemma or accepting that group agency is not wholly rational. Given the onerous costs associated with the former, it seems preferable to abandon a fully unified account of agency in favour of one that incorporates a distinct, minimalist model of group rationality.

Acknowledgements For comments on earlier drafts of this paper, I am grateful to Shane Glackin and an anonymous referee. This work was developed with the financial support of a Fulbright Scholar Award and a New York University School of Law Hauser Research Scholarship.

\section{References}

Arrow, K. (1950). A difficulty in the concept of social welfare. Journal of Political Economy, 58, 328-346.

Bar-On, D., \& Long, D. (2003). Knowing selves: Expression, truth, and knowledge. In B. Gertler (Ed.), Privileged access: Philosophical accounts of self-knowledge (pp. 179-212). Aldershot: Ashgate.

Bratman, M. (1992). Shared cooperative activity. Philosophical Review, 101(2), 327-341.

Chant, S. R. (2007). Unintentional collective action. Philosophical Explorations, 10(3), 245-256.

Chilton, A., \& Tingley, D. (2012). The doctrinal paradox \& international law. University of Pennsylvania Journal of International Law, 34(1), 67-147.

Coleman, J. S. (1972). Collective decisions and collective action. In P. Laslett et al. (Eds.), Philosophy, politics and society (Fourth Series), pp 208-219.

Condorcet, M. D. (1785). Essai sur l'Application de l'Analyse à la Probabilité des Décisions rendues à la Pluralité des Voix Paris.

Copp, D. (1980). Hobbes on artificial persons and collective actions. Philosophical Review, 89(4), 579-606.

Copp, D. (1995). Morality, normativity, and society. New York: Oxford University Press.

Dennett, D. (1991). Real patterns. Journal of Philosophy, 88(1), 27-51.

Durkheim E. (1953). Trans. DF Pocock, Sociology and Philosophy. Glencoe: Free Press

Figgis, J. N. (1913). Churches in the modern state. London: Longmans.

Gertler, B. (2015). Self-Knowledge. In E. Zalta (Ed.), Stanford Encyclopedia of Philosophy. http://plato. stanford.edu/archives/sum2015/entries/self-knowledge/.

Gilbert, M. (1990). Walking together: A paradigmatic social phenomenon. Midwest Studies in Philosophy, 15(1), 1-14.

Hess, K. (2014). The free will of corporations (and other collectives). Philosophical Studies, 168(1), 241-260.

Kornhauser, L., \& Sager, L. (1986). Unpacking the court. Yale Law Journal, 96(1), 82-117.

Kornhauser, L., \& Sager, L. (1993). The one and the many: Adjudication in collegial courts. California Law Review, 81(1), 1-59.

Kornhauser, L., \& Sager, L. (2004). The many as one: Integrity and group choice in paradoxical cases. Philosophy \& Public Affairs, 32(3), 249-276.

Lewis, D. (1973). Counterfactuals. Oxford: Blackwell. 
List, C., \& Pettit, P. (2002). Aggregating sets of judgments: An impossibility result. Economics and Philosophy, 18(1), 89-110.

List, C., \& Pettit, P. (2006). Group agency and supervenience. Southern Journal of Philosophy, 44(Supplement), 85-105.

List, C., \& Pettit, P. (2011). Group agency: The possibility, design, and status of corporate agents. New York: Oxford University Press.

Pettit, P. (2001). Collective intentions. In N. Naffine, R. Owens, \& J. Willlams (Eds.), Intention in law and philosophy, pp 241-254.

Pettit, P. (2003). Deliberative democracy, the discursive dilemma, and republican theory. In J. Fishkin, P. Laslett (Eds.), Philosophy, politics and society, (Seventh Series), pp 138-168.

Pettit, P. (2014). Group agents are not expressive, pragmatic or theoretical fictions. Erkenntnis, 79(9), 1641-1662.

Rawls, J. (1971). A theory of justice. Oxford: Oxford University Press.

Roth, A. S. (2010). Shared Agency. In E. Zalta (Ed.), Stanford encyclopedia of philosophy. http://plato. stanford.edu/archives/spr2011/entries/shared-agency/.

Rovane, C. (2014). Group agency and individualism. Erkenntnis, 79(9), 1663-1684.

Schmid, H. B. (2014). Expressing group attitudes: On first person plural authority. Erkenntnis, 79(9), 1685-1701.

Schweikard, D. (2008). Limiting reductionism in the theory of collective action. In H. B. Schmid, K. Schulte-Ostermann, \& N. Psarros (Eds.), Concepts of sharedness-essays on collective intentionality (pp. 89-117). Frankfurt: Ontos Verlag.

Schweikard, D., \& Schmid, H. B. (2013). Collective intentionality. In E. Zalta (Ed.), Stanford encyclopedia of philosophy http://plato.stanford.edu/archives/sum2013/entries/collectiveintentionality/.

Searle, J. (1990). Collective intentions and actions. In P. Cohen, J. Morgan, \& M. Pollack (Eds.), Intentions in communication (pp. 401-415). Cambridge: MIT Press.

Shpall, S., \& Wilson, G. (2012). Action. In E. Zalta (Ed.), Stanford encyclopedia of philosophy http:// plato.stanford.edu/archives/sum2012/entries/action/.

Tenenbaum, S. (2015). Representing collective agency. Philosophical Studies, 172(12), 3379-3386.

Tollefsen, D. (2002). Collective intentionality and the social sciences. Philosophy of the Social Sciences, $32(1), 25-50$.

Vermeule, A. (2011). The system of the constitution. New York: Oxford University Press.

Wright, C. (2012). Knowledge of our own minds and meanings. In A. Coliva (Ed.), Mind, meaning, and knowledge: Themes from the philosophy of Crispin wright (pp. 402-417). Oxford: Oxford University Press. 